\title{
Engagement in Practice: Socio-technical Project-based Learning Model in a Freshman Engineering Design Course
}

\author{
Dr. Raghu Pucha, Georgia Institute of Technology
}

Dr. Raghu Pucha is a Senior Lecturer at the Woodruff School of Mechanical Engineering, Georgia Institute of Technology, in the area of CAD/CAE and Manufacturing. Dr. Pucha teaches computer graphics and design courses at Georgia Tech., and conducts research in the area of developing computational tools for the design, analysis and manufacturing of advanced materials and systems. Dr. Pucha has three provisional U.S. patents and co-authored over 60 research papers. He is honored with Undergraduate Educator Award in 2012 and Geoffrey G. Eichholz Faculty Teaching Award in 2015 from the Center for Enhancement of Teaching and Learning (CETL) at Georgia Tech.

\section{Dr. Carol J Thurman, Georgia Institute of Technology}

Dr. Carol Thurman serves as the Academic Assessment Manager for Georgia Tech's Center for ServeLearn-Sustain. She holds a doctorate in Educational Policy Studies with a concentration in Research, Measurement, and Statistics. Dr. Thurman's professional experience includes higher education academic and program assessment, program evaluation, project management, teaching K-12 both in the U.S. and internationally, teaching university research and statistics courses, and serving as a K-12 school district research specialist. Dr. Thurman's research interests include transdisciplinary research approaches to understanding and addressing sustainability social issues that reside in the complex space.

\section{Ruth Yow, Georgia Institute of Technology}

Ruthie Yow is the Service Learning and Partnerships Specialist at Georgia Tech's Center for Serve-LearnSustain.

\section{Mr. Connor Rylan Meeds,}

Connor Meeds is a mechanical engineering and business student at the Georgia Institute of Technology. Embarking his research under the guidance of Dr. Pucha within his first year at Tech, Connor has developed multiple case studies with a focus on bringing sustainable engineering methods into classrooms. He aims to develop an efficient method to transform student projects into applicable case studies for eventual real-world application. Outside of the normal engineering curriculum, Connor is an exceptionally motivated entrepreneur in the start-up circle. Bringing up two self-made businesses and working his off-hours at a web-design agency start-up, Connor has high ambitions to bring new ideas into the world. .

\section{Dr. Jennifer Hirsch, Georgia Institute of Technology}

Dr. Jennifer Hirsch is an applied anthropologist specializing in sustainability, cultural diversity, collaborative governance, community development, networks, and experiential education. She is recognized nationally for fostering grassroots participation in sustainability and climate action, using methods from visual and environmental anthropology, popular education, asset-based community development, participatory facilitation, and museum education. Since August 2015, she has been the inaugural Director of the Center for Serve-Learn-Sustain at the Georgia Institute of Technology. Serve-Learn-Sustain is a campus-wide academic initiative launched in January, 2016 to prepare students to use their disciplinary expertise to address the world's most pressing sustainability challenges in ways that advance community well-being and create thriving natural systems. Dr. Hirsch is Adjunct Associate Professor in the School of City and Regional Planning at Georgia Tech and serves on the faculty of The Asset-Based Community Development Institute hosted by DePaul University. 


\section{Engagement in practice: Socio-technical project-based learning model in freshman engineering design course}

\section{Overview and paper organization}

This paper presents ongoing activities that bring social justice and sustainability into the engineering classroom through socio-technical project-based learning. Specifically, the discussion here details activities in a freshman engineering design course supported by a relatively new Georgia Tech initiative with the theme of "creating sustainable communities." The activities in the course pertain particularly to the initiative's vision that all graduates of the institute - a majority of whom will graduate with engineering degrees - are able to contribute to the creation of sustainable communities and to understand the impact of their professional practice on the communities in which they work. The work-in-progress paper is organized with the following content (i) Introduction to "Center for Serve-Learn-Sustain" and freshman engineering course (ii) a description of pedagogical approaches to socio-technical learning, (iii) description of Socio-technical Project-based Learning Model and Assessment methods (iv) development database of socio-technical projects for engineering courses, (v) additional Models and resources from "Center for Serve-Learn-Sustain" and (vi) future directions.

\section{Introduction to "Center for Serve-Learn-Sustain" and freshman engineering course}

In January 2016, Georgia Tech launched a campus-wide academic initiative ("Center for Serve-Learn-Sustain" - name withheld for review) aimed at preparing undergraduate students in all majors to use their disciplinary knowledge and skills to contribute to the major societal challenge of creating sustainable communities. The Center is Georgia Tech's new Quality Enhancement Plan (QEP), a key component of the Georgia Tech's reaffirmation of accreditation with the Southern Association of Colleges and Schools. The initiative collaborates with faculty in all six Georgia Tech colleges to develop courses and co-curricular opportunities that will help students learn about sustainability and community engagement and hone their skills by engaging in real-world projects with nonprofit, community, government, and business partners. 
Over the past two years, the Center has worked closely with a diverse group of faculty to develop an experientially-based pedagogical framework for engaging science and technology majors in sustainable communities' education - and to try it out in different classes. This paper presents that framework and reports on one engineering instructor's efforts to put it into practice by revising a core course in Mechanical Engineering. This course was one of more than 100 Center-affiliated courses offered during AY2016-17, enrolling over 5,000 students across all six colleges - including Engineering, Computing, Design, Liberal Arts, Business, and Sciences. It was one of 24 courses offered in the College of Engineering. In addition to addressing course-specific learning outcomes, Center-affiliated courses are expected to address one or more of the Center's four learning outcomes related to sustainability and community engagement, which are:

Develop Knowledge \& Skills

1. Students will be able to identify relationships among ecological, social, and economic systems.

2. Students will be able to demonstrate skills needed to work effectively in different types of communities.

3. Students will be able to evaluate how decisions impact the sustainability of communities.

Connect to Professional Practice

4. Students will be able to describe how they can use their discipline to make communities more sustainable.

Affiliated courses address various aspects of the Center's sustainable communities framework, which presents sustainability as an integrated system connecting environment, economy, and society, and focuses especially on society - particularly social equity and community voice - to address this gap in technological education. Drawing on pedagogical

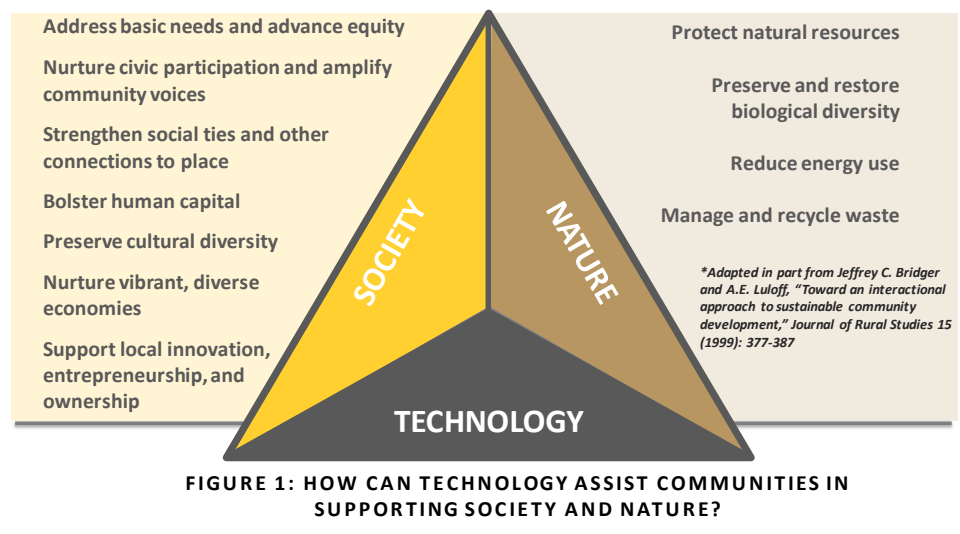
research related to sustainable development and social justice, especially regarding engineering education, the framework asks faculty to help students understand how 
technology can assist or empower communities in their efforts to create places in which people and nature flourish, now and in the future (see Figure 1).

A Socio-technical project-based learning model is currently used in a freshman-engineering course. Contextualized design problems are assigned to engage students throughout the course.

This freshman course involves understanding the overall aspects of engineering design process and the specific role of graphics and visualization at various stages of engineering design. It is a required course for Civil, Mechanical and Aerospace engineering students. Typically in each Spring and Fall this course attracts around 400 students with a class size of 40. Successful completion of this course demands working independently on lecture activities, 3 hour lab activities every week throughout the semester and working in a group environment for the final project. Overall the course is taught citing various examples from Engineering Design process through project-based learning and correlating the role of Engineering Graphics and Visualization at various stages. In Fall 2016 this course was affiliated to "Center for Serve-Learn-Sustain" with socio-technical based project-based learning. Design-based activities that incorporate social justice and sustainability are engaged through both individual and team projects. In individual projects, students work on product designs with external representations promoting sustainable resource-use to motivate people to make decisions and commit to behaviors that sustain resources. Designs with external representations promoting sustainability also lower the cognitive load involved in sustainability decisions (Chandrasekharan and Tovey, 2012). Complementing work done in individual projects, the team projects' focus and goals include designing products that facilitate (i) attending to context and listening to user populations for problem definition, (ii) identifying structural conditions and (iii) acknowledging local community/mobilizing power (Leydens and Lucena, 2017).

\section{Literature and Pedagogy}

The Center's central pedagogical approach is project-based learning, and specifically, working with community partners to address sustainability challenges from communitybased perspectives. As such, a key concern is helping engineering students focus on 
problem-framing before they jump into problem-solving. Specifically, we help students contextualize their projects so they understand technological solutions as one piece of a larger puzzle. As scholar Juan Lucena has suggested, there has been in the last ten years a wellspring of scholarly interest and activity in problem- and project-based learning in what he broadly calls a "humanitarian" context. Lucena offers a critical vantage point on the legacy of humanitarianism in engineering by analyzing the traditional positing of engineers as emissaries of and authorities on "technology to "relieve the suffering of these people" (2015:16), pointing toward an imagined community of "people" who await salvation by American engineers. A "critical engineering education," as outlined by Lucena, is one that equips students to be critical of such narratives and attentive to structural inequities, to seek projects that emerge from the community, to engage the expertise of community members, and to co-create, with local partners, structures that support an ongoing relationship, such that both the engineering "solution" and the collaboration between engineering students and community members can be sustained and nurtured.

Projects affiliated with the Center draw on Lucena's notion that "technological solutions might not necessarily lead to sustainable community development since the practices that support communities reside at the local level" (Lucena 2015:6). It is at the local level that engineering students encounter the ways in which sustainable development actually unfolds in daily life, within a complex web of historical and political relationships, making community-based projects challenging at registers beyond the technical and theoretical. As scholars Bridger and Luloff write, successful community-based projects - those that exemplify carefully implemented socio-technical solutions-will have as their foundation "purposive actions ... [that] develop relationships and lines of communication across interest lines [and] . . . linkages [that] . . create trust and foster mutual understanding" (1999:384). Creating institutional infrastructure for students to "develop relationships" in the context of community-based projects as well as introducing them to critical frameworks that help them analyze the impacts of their professional practice within communities amounts to "constructively challenging . . . 
students to connect technical areas [their training and coursework] to social justice" (Lucena, 2015: 16).

The Center's approach to socio-technical projects is distinguished by the wedding of an orientation toward justice and equity with an emphasis on technology as only one element of dynamic interplay among society, technology, and nature. Service-learning scholars Susan Cipolle and Tania Mitchell both offer key insights on this question of how project-based learning in engineering can engage local communities through social justice frameworks. Cipolle suggests a "co-created curriculum," one in which students and professors are engaged in the development of critical perspectives on social problems and on ways to produce solutions in collaboration and dialogue with community partners. Relatedly, Tania Mitchell, who reshaped the academic dialogue on service-learning and community-based learning, challenges the ways that "traditional service learning" leaves structural inequality unexamined, failing to guide students toward an understanding of its roots. What Mitchell calls "a social change orientation" and an aim to "redistribute power" distinguish critical service learning from traditional service learning. Drawing on this critical service-learning framework, the Center aims to facilitate transformational learning for students as well as the foundations for longer-term relationships within communities.

To prepare engineering students with critical perspectives and deep context for local community-engaged work without sacrificing disciplinary rigor is a pressing challenge, and it has been taken up fruitfully by scholars of service learning in engineering. Work by Williams Oakes (Engineering Projects in Community Service at Purdue) and Marybeth Lima (LSU) has focused on how to "teach" students to engage with the community aspect of project-based learning. Rather than foisting projects on student groups, and those groups on community partners without preparation or pedagogical support, Oakes and Lima emphasize the importance of robust institutional and intellectual architecture for service-learning projects in engineering. Envisioning the project as having outcomes at three registers-discipline/skill specific, "personal values," and "social systems and issues"-Lima and Oakes reinforce the importance of creating a trajectory for students that fosters their team-based, analytical, communication, and creative thinking skills in 
the context of a sustained and reciprocal relationship with a community partner (2006: 309). When students are offered ways to engage in critical service learning and are taught through critical engineering frameworks, they-and their instructors and institutions - are positioned to "broaden the narrow technical focus" of engineering education and see themselves as co-learners and co-teachers in project-focused relationships (Lucena 2015, p. 16). Further, when this form of collaboration is privileged, then relationships no longer have as their focus a given project or deliverable but rather those relationships endure and are nourished by their place in a broader network to effect deeper and more systemic local, national, or international change.

\section{Socio-technical Project-based Learning Model and Assessment}

An engineering instructor should play an important role in leading students to view social and ethical choices as vital parts of their future lives, both as professionals and as citizens. Traditionally engineering has been viewed purely as a technical problem-solving discipline (Lucena 2015), pushing engineers into the real world with a "one-size-fits-all" approach. Consequently, advanced technological solutions to problems around the world are being carried out with little understanding of the solution's local economic, social, and/or environmental impacts. To bring about social justice and sustainability through engineering solutions, values and ethics must be at the forefront of current engineering curricula. This paper presents ongoing activities that bring social justice and sustainability into the classroom through socio-technical project-based learning in a freshman engineering design course. Through the contextualization of real-world problems and solutions within detailed case studies, students analyze ethically complex scenarios and develop value-based skills during the design, implementation, and evaluation stages of their engineering solution. Table 1 lists the difference in traditional engineering design and socio-technical Engineering design activities taken in this class, influenced by the Center and, in particular, the work of Juan Lucena. 
Table1: Socio-technical framework in Freshman Engineering Design Course

\section{Traditional Engineering Design}

- Traditionally engineering is viewed as a technical problem solving discipline.

- Engineer is identified as problem solver - not problem definer.

- Assumes Communities are homogeneous entities with one voice and can be treated as a "client" or "customer". For many design means "design for Industry".

- University training in problem solving is primarily done using decontextualized text-book problems. One-size-fitsall approach.

- Development and modernization with technology to transform society focused

\section{Socio-technical Engineering Design}

- Socio-technical problem solving (Enhance human capabilities, opportunities and resources. Decrease risks and harms)

- Engineers need to understand structural conditions (who suffers/who benefits).

- Listening to community - "design-for-community"

- Define design problems with context (Humancentered problem rewriting).

- Technology to transform society vs society transform technology.

- Socio-technical project database and tools for assessment of students work on sustainability.

The socio-technical approach addresses the ABET learning outcome stating that students should develop "an ability to design a system, component, or process to meet desired needs within realistic constraints such as economic, environmental, social, political, ethical, health and safety, manufacturability, and sustainability" - an outcome not reflected in much current curricula. This approach actually goes further, emphasizing understanding social context as an asset rather than a constraint, and engaging community as collaborators to develop better solutions.

Table 2: Socio-technical Project-based Learning Model

\begin{tabular}{|c|c|c|}
\hline $\begin{array}{l}\text { Examples of Socio-technical project-based learning } \\
\text { activities in the course }\end{array}$ & $\begin{array}{l}\text { Social / Sustainability Aspects and } \\
\text { Learning outcomes }\end{array}$ & Technical / Design Aspects \\
\hline $\begin{array}{l}\text { Lab Activity: Do research on Recycling bins in } \\
\text { Barcelona .Identify structural conditions and come } \\
\text { up with a creative design idea for futuristic (curvy, } \\
\text { sleek, stylish and unique) Public Recycling Container } \\
\text { with all features for University Campus (see Figure 2) }\end{array}$ & $\begin{array}{l}\text { The problem is identified contextually. } \\
\text { Students will be able to evaluate how } \\
\text { decisions impact the sustainability of } \\
\text { communities }\end{array}$ & $\begin{array}{l}\text { Use of Creative Ideation } \\
\text { methods and sketching of } \\
\text { design ideas using orthographic } \\
\text { projections. }\end{array}$ \\
\hline $\begin{array}{l}\text { Individual Project: One person's sustainable choices } \\
\text { can be neutralized by others' wasteful behavior. } \\
\text { Product design with external representations } \\
\text { promoting sustainable resource-use need to } \\
\text { motivate people to make decisions that sustain } \\
\text { resources, and persist with this behavior. Design } \\
\text { creative and unique appliances that promote } \\
\text { sustainable use of natural resources for Home \& } \\
\text { office use of university community. (see Figure 2) }\end{array}$ & $\begin{array}{l}\text { Responsible consumption and } \\
\text { sustainability. Increasing Opportunities } \\
\text { and Resources. Reducing Imposed Risks } \\
\text { and Harms. Enhancing Human } \\
\text { Capabilities. Students will be able to } \\
\text { describe how their actions impact the } \\
\text { sustainability of communities. }\end{array}$ & $\begin{array}{l}\text { Use of Creative Ideation } \\
\text { methods and sketching of } \\
\text { design ideas using orthographic } \\
\text { projections. Use external } \\
\text { representation concepts for } \\
\text { sustainable design. Use of CAD } \\
\text { and 3D printing to create and } \\
\text { defend a worthy design proposal } \\
\text { for a desired product. }\end{array}$ \\
\hline $\begin{array}{l}\text { Team Project: Low-cost dehumidifiers as a potential } \\
\text { solution for reducing public health risks associated } \\
\text { with mold and mildew in nearby community. The } \\
\text { water vapor removed from air in homes could } \\
\text { potential be reused for gardening and dehumidifiers } \\
\text { that utilize solar energy may not have a huge impact } \\
\text { on energy bills. Alternative Low-cost multi-purpose } \\
\text { de-humidification approaches and designs are also } \\
\text { encouraged. (see Figure } 2 \text { ) }\end{array}$ & $\begin{array}{l}\text { The problem is identified contextually. } \\
\text { During design, the structural conditions } \\
\text { are identified meeting community } \\
\text { needs. Mobilize available sources of } \\
\text { power to enact a more socially } \\
\text { justifiable engineering product. } \\
\text { Students will be able to describe how } \\
\text { they can use their discipline to make } \\
\text { communities more sustainable. }\end{array}$ & $\begin{array}{l}\text { Ideation, sketching, design and } \\
\text { assembly of large scale } \\
\text { engineering structure. }\end{array}$ \\
\hline
\end{tabular}


Figure 2 shows examples of student work on socio-technical project-based learning activities described in Table 2 and ongoing assessment of student post-activity reflections on socio-technical project-based learning and assessment rubrics for evaluating students' projects.

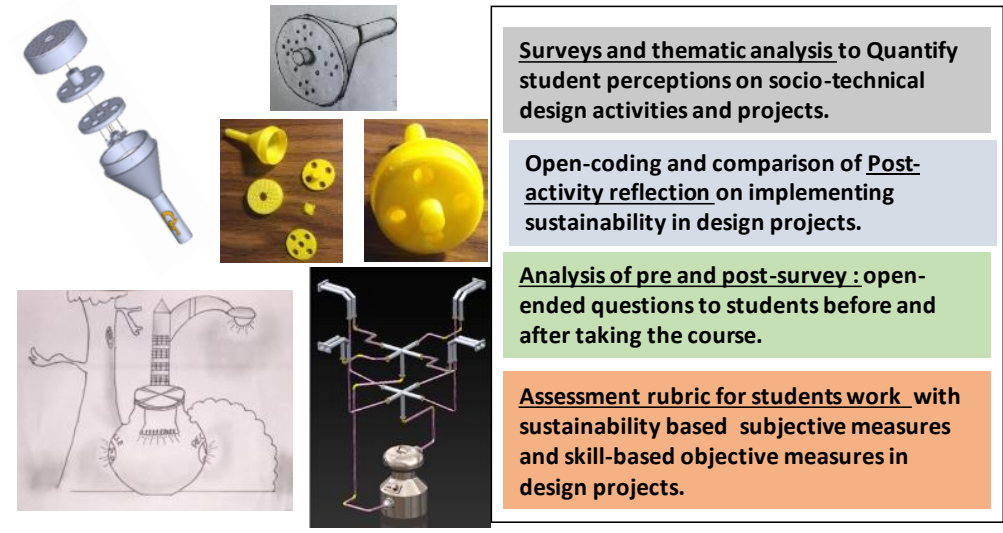

Figure 2: Student work examples and Assessment Approach

As explained in Table 2, Figure 2 shows examples of student work in lab activity (design of recycling bin for campus), individual project (Showerhead design with external representations promoting sustainable resource-use) and team project (Low-cost dehumidifiers that have been suggested by local community leaders as a potential solution for reducing public health risks associated with mold and mildew). We will use a mixed-methods methodology in our approach to assessing our student data. Student reflections will be analyzed using a grounded theory approach whereby results emerge through consideration and analysis of the data. We will use NVivo 11 Plus, a qualitative data analysis software tool to accomplish this phase. The first step will include open coding of the data where we will examine student reflections for distinct, separate ideas or experiences and code each segment into categories. The second step - axial coding will involve reexamining the student reflections for identifying relationships between categories and themes identified during open coding. In the final step, a core category will be developed which is the overarching category under which the other categories and subcategories belong. The quantitative phase will involve using a rubric to score student reflections; a numeric score will be assigned to each reflection in the sample and the group average will be calculated. Results on some of these assessments will be presented and discussed during the conference.

Development of Socio-technical case studies database: While university training in problem solving is primarily done using decontextualized text-book problems, engineers are required to develop problem defining skills in addition to solving them. Too many 
engineering solutions are failing with their disregard for communal understanding of the solution, realistic maintenance requirements, naturally available resources over imported materials, and/or the customs of the community. To combat this problem, a database of contextualized socio-technical projects are compiled describing the details of the socio-technical problems, stake holders involved and a list of available local resources is being developed (see Figure 3 for examples of socio-technical design projects undertaken by students). In the team projects, students are asked to do more research on the chosen sociotechnical project from the database, to design a simple, low-tech, low-cost, locally-sourced, and flexible design process. For example, students (team of 5) that chose IKEA housing project

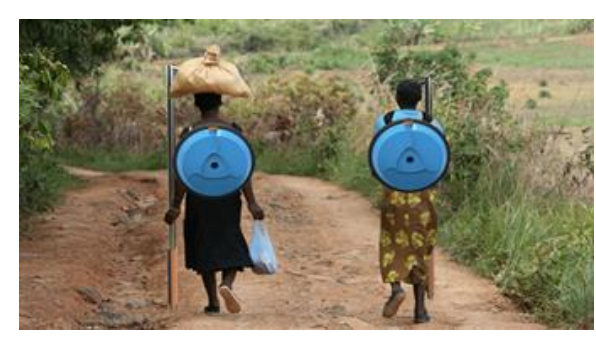

Water Transportation Device for Sub-Saharan Africa https://cdn.trendhunterstatic.com/thumbs/water-transportation.jpeg

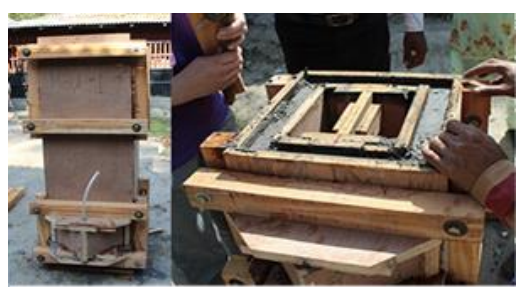

Water Purification Device for Cambodia

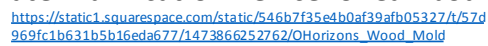

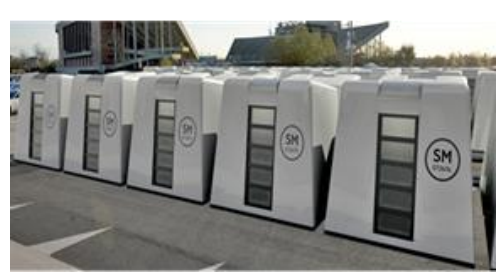

IKEA Housing Set for Refugees in Ethiopia hittps://inhabitat.com/wp content//loges

Figure 3: Some student projects from Database from the database will give a detailed proposal to the instructor on alternative sustainable designs on housing for refugees. In the proposal students are asked to clearly identify various sustainability aspects that are considered in the design including structural conditions meeting community needs (who benefits and who suffers), acknowledging political agency/mobilizing, increasing opportunities and resources, reducing imposed risks and harms posed by environment and natural disaster, enhancing human capabilities etc.

After approval, students work on design sketches, CAD models and system level assembly of CAD models and functional designs with a detailed report for assemment. Their final projects are then being re-written as case studies to share with future students and other faculty. These case studies will eventually be housed in the Center's Teaching Toolkit - a library of lesson-planning resources that help instructors integrate sustainability, community engagement, and service-learning into their courses. 


\section{$\underline{\text { Additional Models and Resources from "Center for Serve-Learn-Sustain" }}$}

For scholars, administrators, and program staff at institutions seeking to establish or improve socio-technical problem-based learning in their engineering curricula, there are several excellent models and resources. The aforementioned EPICS program is not only represented in key scholarly works on project-based learning but the program website also hosts a variety of documents that provide insight on program structure at the level of both the individual and the team; "Team Documents" include "Design Document" "Design Review," and "Transition Checklist" (for onboarding new project team members), while Individual documents include Syllabi, Reflections, and Individual Evaluation Rubric. These resources allow readers to engage with the program's infrastructure and organization as well as its solutions to logistical challenges posed by projects with multiple stakeholders - such as the use of SharePoint for all team documents, or the "Milestones" system which establishes a timeline common to all project teams.

Other leaders in the field have similarly produced publically available documents for the specific purpose of making accessible best practices in project-based learning that is community engaged and STEM-oriented. Katja Brundiers of the School of Sustainability at Arizona State University and Fletcher Beaudoin of the Institute for Sustainable Solutions at Portland State University -both thought leaders in real-world project-based learning - collaborated on "A Guide for Applied Sustainability Learning Projects: Advancing Sustainability Outcomes on Campus and in the Community" (March 2017). This guide, downloadable for free via the website of the Association for the Advancement of Sustainability in Higher Education (AASHE), offers insight on how to establish and scale socio-technical project based learning; the authors offer twenty-six activities (which are sustainability focused, but the applicability is broad) that apply to one of four phases the authors identify for building programs around real-world projectbased learning: Predevelopment Phase, Takeoff Phase, Acceleration Phase, and Stabilization Phase. Activities categorized in the "Predevelopment Phase" -the phase in 
which a number of socio-technical projects have been undertaken but are not yet connected to a program or Center-are broadly helpful as they outline ways to produce and refine the type of case study database described in this paper, including engaging the model the authors offer for "Interaction between Students and the World." This model describes four successive stages: Bringing the World In (Level 1); Visiting the World (Level 2); Simulating the World (Level 3); and Engaging with the World (Level 4): the authors propose these stages as unfolding over a four-year college experience, rather than over the course of a single semester. Finally, the Center with which the authors are affiliated offers tools - through its web-based Teaching Toolkit - that are relevant to instructors engaging in socio-technical project based learning with or without partners. Tools available in the Teaching Toolkit include in-class activities that help students establish context for projects by lending insight into how problem-framing and solutionsoriented approaches often do not incorporate an "asset-based" understanding of communities or engage with historical inequities that produced the challenges that engineering students may be tasked with in a problem-based learning setting. Relevant tools that are searchable on our Center's Teaching Toolkit website include "Society, Equity, and Sustainability," "Asset Based Community Development," and "Service Learning and Community Engagement (SLCE) Nuts 'n Bolts" (a resource for instructors who would like logistical support in courses with community partners). Such tools can be used in ways that enrich the curriculum in both upper-level engineering courses and survey courses as their activities and readings can be adapted to any timeframe or pedagogical format (i.e. discussion or lecture-based). The suggested materials and resources described here are all internet accessible and not pay-wall-protected; therefore these materials are shareable among stakeholders, partners, and collaborators who are not necessarily affiliated with academic institutions.

\section{Future Directions}

This paper has reported on initial efforts to develop and implement a socio-technical approach to Engineering Design in one engineering course affiliated with the Center. While it has made significant strides incorporating community-based sustainability perspectives, these have remained largely theoretical. The next important step is to work 
with the Center's staff, and potentially as part of the Center's course design programs bringing together partners with faculty from different disciplines, to incorporate closer connections to real-world partners and projects, so that students have direct interactions with community partners and, ideally, do project work that might be of some benefit to a real community. Additionally, the instructor plans to work with Center staff to expand the curricular approach he has developed to other sections of the same course taught by other faculty.

\section{References:}

1. Lucena, Juan. "Bridging sustainable community development and social justice." International Perspectives on Engineering Education. Springer, Cham, 2015. 225247.

2. Jon A. Leydens, Juan C. Lucena Engineering Justice: Transforming Engineering Education and Practice (IEEE PCS Professional Engineering Communication Series), Wiley-IEEE Press, Dec 18, 2017.

3. Chandrasekharan, S. and M. Tovey, Sum, quorum, tether: Design principles underlying external representations that promote sustainability. Pragmatics \&amp; Cognition, 2012. 20(3): p. 447-482.

4. Bridger, Jeffrey C., and Albert Elliot Luloff. "Toward an interactional approach to sustainable community development." Journal of rural studies 15.4 (1999): 377387.

5. Cipolle, Susan Benigni. Service-Learning and Social Justice: Engaging Students in Social Change. Rowman \& Littlefield Publishers, 2010.

6. Mitchell, Tania D. "Traditional vs. Critical Service-Learning: Engaging the Literature to Differentiate Two Models." Michigan Journal of Community Service Learning 14.2 (2008).

7. Oakes, William and Marybeth Lima. Service Learning Engineering in Your Community. St. Louis, MO: Great Lakes Press, 2006. 